\title{
Determining the season of death from the family composition of insects infesting carrion
}

\author{
Thiago de Carvalho MORETti ${ }^{1}$, Vinícius BONATO² and Wesley Augusto Conde GODOY ${ }^{3}$ \\ ${ }^{1}$ Departamento de Parasitologia, Instituto de Biociências, Universidade Estadual Paulista "Júlio de Mesquita Filho", Botucatu, \\ São Paulo, 18618-000, Brazil; e-mail: tcmoretti@yahoo.com.br \\ ${ }^{2}$ Pfizer Inc., Groton, Connecticut, 06340, USA; e-mail: vinibonato@yahoo.com.br \\ ${ }^{3}$ Universidade de São Paulo, Escola Superior de Agricultura Luiz de Queiroz (ESALQ), Piracicaba, São Paulo, 13418-900, Brazil; \\ e-mail: wacgodoy@esalq.usp.br
}

Key words. Forensic science, forensic entomology, necrophagous insects, seasonal dating, seasonality, Calliphoridae, Sarcophagidae, Fanniidae, Formicidae, baseline-category logit model

\begin{abstract}
Determining the season of death by means of the composition of the families of insects infesting carrion is rarely attempted in forensic studies and has never been statistically modelled. For this reason, a baseline-category logit model is proposed for predicting the season of death as a function of whether the area where the carcass was exposed is sunlit or shaded and of the relative abundance of particular families of carrion insects (Calliphoridae, Fanniidae, Sarcophagidae, and Formicidae). The field study was conducted using rodent carcasses (20-252 g) in an urban forest in southeastern Brazil. Four carcasses (2 in a sunlit and 2 in a shaded area) were placed simultaneously at the study site, twice during each season from August 2003 through June 2004. The feasibility of the model, measured in terms of overall accuracy, is $64 \pm 14 \%$. It is likely the proposed model will assist forensic teams in predicting the season of death in tropical ecosystems, without the need of identifying the species of specimens or the remains of carrion insects.
\end{abstract}

\section{INTRODUCTION}

The microenvironment to which a carcass is exposed (e.g. shaded or sunlit sites), which affects local air temperature, humidity and rate of dehydration, has a major effect on (i) the rate of decomposition of the carcass, (ii) its attraction as an oviposition/larviposition site for flies, (iii) maggot development and (iv) relative abundance of carrion insects (Shean et al., 1993).

Another major factor is the season of the year, which has a crucial influence on weather and on the biotic community of a region, and may also affect both the decomposition process and the composition of the carrion entomofauna (Tomberlin \& Adler, 1998).

The season is even more important than the time that has elapsed since death in determining the time of colonization of several species of carrion insects, mainly in temperate countries (Anderson, 2010).

The seasonality of some carrion arthropods and the different times of colonization of a carcass in different seasons imply that these organisms may be valuable in determining the season of death, which is especially useful when a corpse is discovered long after death occurred (i.e. long PMI cases) (Anderson, 2010). Establishing the season of death can be crucial in determining/eliminating suspects and confirming alibis in the case of murder, accidental death, suicide and even when the death is from natural causes (Schoenly et al., 1992; Geberth, 1996). The season of death can also have important implications for legal matters such as inheritance and insurance (Henssge et al., 2002).
In spite of its importance, the association between carrion insects and their season of appearance on corpses, and therefore the possibility of predicting the season of death using these organisms, has rarely been investigated (but see, e.g., Archer \& Elgar, 2003), and, to the best of our knowledge, has never been statistically modelled.

For this reason, it is proposed here to use a statistical approach, a logit-based regression method, to model the season in which death occurred in terms of a function of the area where the carcass was exposed (sunlit or shaded) and the relative abundance of arthropod families found in the carrion. This type of model, which is unusual in the field of forensic entomology, is called a logit model, or specifically in our case, a baseline-category logit model (Agresti, 2002). This type of statistical approach was chosen to build a model able to describe the probability of occurrence of a nominal event (season) as a function of a set of independent covariates. A cross-validation procedure was used to validate the model and assess its accuracy in predicting the season in which death occurred.

\section{MATERIAL AND METHODS}

\section{Study site}

The site was located in an urban forest $\left(22^{\circ} 49^{\prime} 15^{\prime \prime} \mathrm{S}\right.$, $\left.47^{\circ} 04^{\prime} 08^{\prime \prime} \mathrm{W}\right)$ on the campus of the State University of Campinas (UNICAMP) in the municipality of Campinas, São Paulo State, Brazil (approx. $685 \mathrm{~m}$ above sea level). The climate of the region is seasonal, with a dry and cool season (winter) occurring from early June to late August, a warm and wet season (summer) from mid-November to late March, and two transitional periods characterized by oscillations in temperature and 

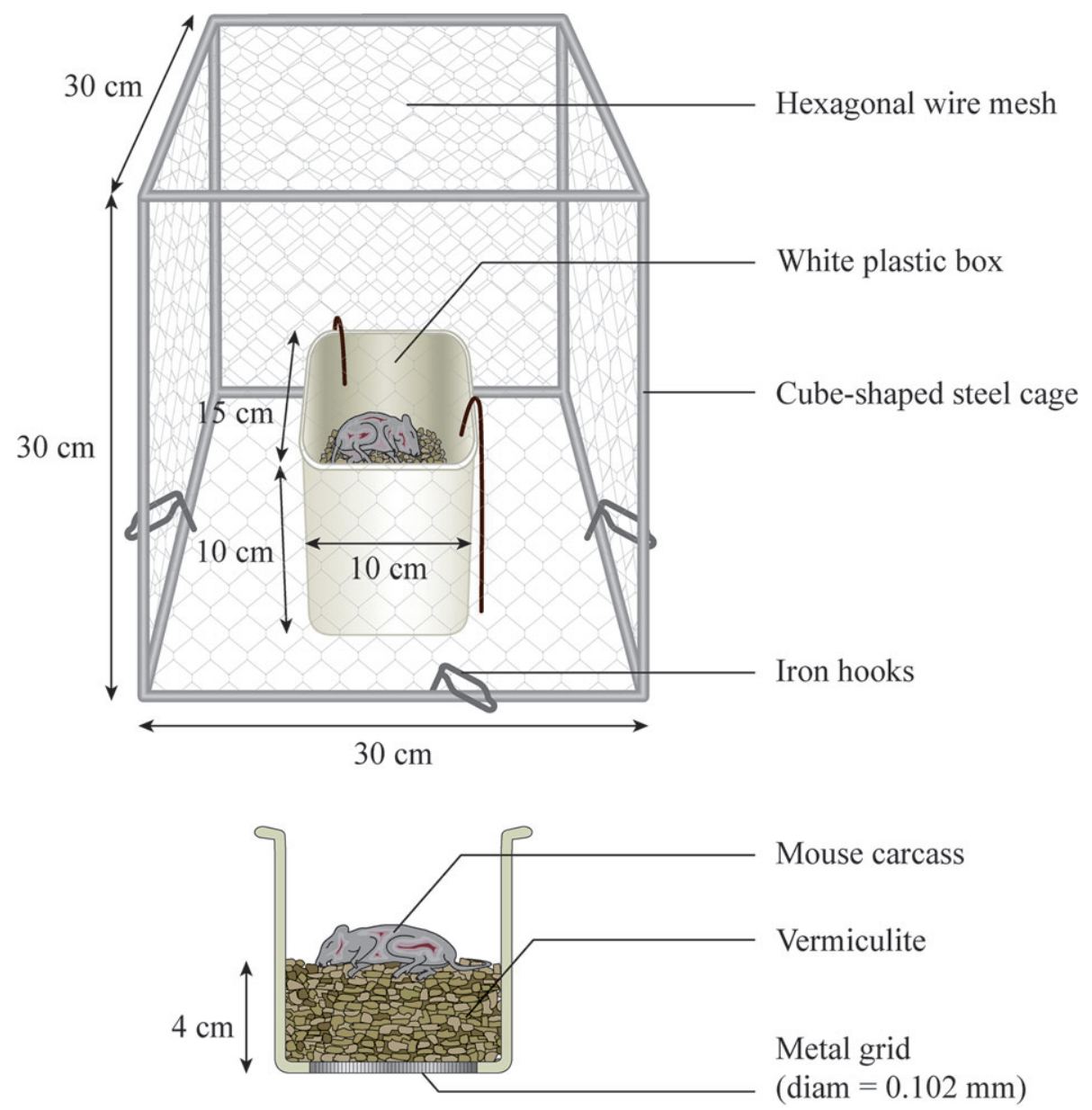

Fig. 1. Device used to carcass exposure in the field.

rainfall: early April to late May (autumn) and early September to early November (spring). The mean temperature of the coldest month is $18.5^{\circ} \mathrm{C}$ and that of the hottest month is $24.9^{\circ} \mathrm{C}$. The mean annual rainfall is $119 \mathrm{~mm}$ (CEPAGRI-UNICAMP; Souza \& Linhares, 1997).

\section{Model}

16 carcasses of mice (Mus musculus Linnaeus) and 16 of albino rats (Rattus norvegicus Berkenhout), ranging from 20 to $252 \mathrm{~g}$, were used. Rodent carcasses are widely used in studies on insect colonization of carrion (Monteiro-Filho \& Penereiro, 1987; Blackith \& Blackith, 1990; Kentner \& Streit, 1990; Isiche et al., 1992; Moura et al., 1997; Tomberlin \& Adler, 1998, Davies, 1999).

\section{On-site and laboratory procedures}

The field study was carried out from August 2003 through June 2004. Two mice and two rat carcasses were placed simultaneously at the study site twice in each season (with an interval of 30 days between placing out the first and second batch of carcasses), with a total of 32 rodents and 8 experiments during the 4 seasons.

The carcasses were placed in individual white plastic boxes $(15 \times 10 \times 10 \mathrm{~cm})$, and arranged $20 \mathrm{~m}$ apart in either sunlit or shaded areas in the forest (one mouse and one rat in both the sunlit and shaded areas). No interaction between the carcasses placed in the different areas (e.g. transfer of odours of decomposition) was detected. A thin metal grid (diam $=0.102 \mathrm{~mm})$ at the bottom of the box allowed water to flow through while preventing adults and maggots from leaving.
There was a 4-cm-thick layer of vermiculite between the metal grid and the carcass, which absorbed rainwater and provided a substrate for pupation. A cube-shaped steel cage $(30 \times$ $30 \times 30 \mathrm{~cm})$ covered with one-inch hexagonal wire mesh was placed over the plastic box and fixed to the ground with four iron hooks. This cage prevented access by vertebrate scavengers while allowing arthropods to enter. Fig. 1 shows the device used in the present study. Each day, for 30 min between 10:00 and 14:00 h, each carcass was observed. A hand net was used to collect flying insects and tweezers the crawling arthropods (ants, beetles and harvestmen) directly from the carcasses. All collections were performed by the same person throughout the field study.

In the laboratory, all adult insects collected were placed in plastic vials, labelled with place and date of collection and stored at $-20^{\circ} \mathrm{C}$ for later identification. Weather conditions in the field were measured daily during insect collection, with a Celsius thermometer and a humidity sensor. Further meteorological data (e.g. Max/Min daily temperatures) were obtained from a meteorological station, adjacent to the study site, located at $640 \mathrm{~m}$ above sea level. Each field experiment ended when the carcasses were no longer visited by adult insects.

Immature specimens (larvae and pupae) were collected from the vermiculite layer at the end of the experiment. They were reared under controlled laboratory conditions $\left(25 \pm 1^{\circ} \mathrm{C}, 60 \pm\right.$ $10 \%$ relative humidity), in vials containing only a layer of vermiculite and covered with transparent fabric. All insects that emerged were stored at $-20^{\circ} \mathrm{C}$ for later identification. 
TABLE 1. Total number of individuals of the various families of arthropods collected from the 32 rodent carcasses.

\begin{tabular}{lc}
\hline Specimens $^{1}$ & Abundance (n) \\
\hline Order Diptera & 5,284 \\
Calliphoridae $^{2}$ & 380 \\
Sarcophagidae $^{2}$ & 258 \\
Fanniidae $^{2}$ & 122 \\
Otitidae & 75 \\
Syrphidae & 25 \\
Drosophilidae & 22 \\
Muscidae & 16 \\
Micropezidae & 14 \\
Dolichopodidae & 09 \\
Sepsidae & 03 \\
Phoridae & 02 \\
Richardiidae & 01 \\
Anthomyiidae & 01 \\
Asilidae & 01 \\
Lauxaniidae & \\
Order Hymenoptera & 179 \\
Formicidae & \\
Encyrtidae & \\
Apidae & 67 \\
Ichneumonidae & 29 \\
Order Opiliones & 04 \\
Gonyleptidae & \\
Order Coleoptera & 17 \\
Staphylinidae &
\end{tabular}

${ }^{1}$ Includes adults and larvae.

${ }^{2}$ Families included in the reduced model.

${ }^{3}$ Represented by Tachinaephagus zealandicus Ashmead, a parasitoid of the larvae of the blowfly Chrysomya megacephala Fabricius (Moretti \& Ribeiro, 2006).

\section{Statistical modeling of the data}

The season when the carcasses were exposed to arthropod visitation was represented by a nominal response variable $Y$ with $J=4$ categories (autumn, winter, spring and summer). The probability of a carcass being exposed in season $j$, for example is described by letting $j=1$ represent a carcass exposed in autumn, given a fixed setting $x$ of explanatory variables as $\pi_{1}(x)$ $=P(Y=1 \mid x)$. Since $\Sigma_{j} \pi_{j}(x)=1, Y$ follows a multinomial distribution with probabilities $\left\{\pi_{1}(x), \ldots, \pi_{4}(x)\right\}$ and, therefore, the vector of probabilities $\pi_{j}$ 's can be modelled as a function of its covariates $x$ using the baseline-category logit model described by Agresti (2002). The value of this model is that it describes the data and can easily be used to predict the season $j$ of placement of the carcass. The baseline-category logit model uses separate binary logit models for describing the log odds of any event $j$ with respect to a baseline event $J$ (arbitrarily chosen), such that

$$
\log \left(\frac{\pi_{j}(x)}{\pi_{J}(x)}\right)=\beta_{j}^{\prime} x, j=1,2, \ldots, J-1
$$

where the vector $\beta_{j}$ represents the unknown effects to be estimated and $x$ represents the $n \times p$ matrix, with the first column containing the indicator variable for the sunlit area and the remaining columns containing the counts of visiting specimens for each arthropod family $p$ observed at each carcass sample $n$. These covariate effects vary according to the category $j$ paired with the baseline; however, the effects for any other pair $(a, b)$ of response categories can be obtained using

$$
\log \left(\frac{\pi_{a}(x)}{\pi_{b}(x)}\right)=\log \left(\frac{\pi_{a}(x)}{\pi_{J}(x)}\right)-\log \left(\frac{\pi_{b}(x)}{\pi_{J}(x)}\right) .
$$

TABLE 2. Number of individuals (by season) of the families used in the reduced model.

\begin{tabular}{lcccc}
\hline \multirow{2}{*}{ Family (n) } & \multicolumn{4}{c}{ Season } \\
\cline { 2 - 5 } & Autumn & Summer & Spring & Winter \\
\hline Sarcophagidae & 75 & 37 & 32 & 239 \\
Calliphoridae & 648 & 1,637 & 2,640 & 359 \\
Fanniidae & 6 & 105 & 137 & 10 \\
Formicidae & 91 & 0 & 88 & 0 \\
\hline
\end{tabular}

Once the Maximum Likelihood Estimates (MLE) of the vector $\beta_{j}$ is obtained, the probability $\pi_{j}(x)$ of each nominal response of the variable $Y$ can be obtained using the equation

$$
\pi_{j}(x)=\frac{\exp \left(\beta_{j}^{\prime} x\right)}{1+\sum_{j=1}^{J-1} \exp \left(\beta_{j}^{\prime} x\right)}
$$

setting the remaining $\beta_{J}=0$. By fixing $x_{p-1}$ it is possible to obtain the marginal effects of any $x_{p}$ on $\pi_{j}(x)$.

Initially the full model was fitted including the area where the carcass was placed (sunlit or shaded area) and the counts of all arthropod families found on it (including larvae and adults). There appeared to be no plausible biological reason to include interactions in this model. The backward selection procedure was used to find the best model (Draper \& Smith, 1981). This procedure starts with the full model (all main factors), and the least-significant variables are excluded one at a time. The model is refitted at each stage if the significance is below the threshold of $\alpha=1$ based on the $x^{2}$ statistic (Agresti, 2002). A measure of goodness-of-fit of the model is the ratio $(r)$ of the deviance statistic $(D)$ to its degrees of freedom. The closer $r$ is to 1 , the better is the fit of the model (McCullagh \& Nelder, 1989).

In the absence of truly independent data (the situation considered here) the predictive accuracy of the proposed model can be estimated as follows. The samples are split into mutually exclusive training ( $3 / 4$ of the samples) and test sets (remaining $1 / 4$ of the samples). For the training set, the counts of arthropods in the carcasses along with the area (sunlit/shaded) and season of sample are used to build the model. No data from the test set are used in the model construction. The model is then considered to be representative of the model built using all samples (of which the training set is a subset). The test set is used to evaluate the performance of the model built from the training set: for each sample in the test set, season is predicted from the area (sunlit/shaded) and counts of arthropods data. The predicted season (season with highest predicted probability of occurrence) is then compared to the observed data and summarized in terms of accuracy, i.e., given the vector $\widehat{\beta}$ of estimated parameters using the training data, the nominal response of a sample was predicted from the validation data set using $\hat{j}=\arg \max \{P(Y=j \mid \beta, x)\}$. To avoid dependency on the choice of the training and test set, this procedure is randomly repeated for 10 splits. Since the vector $J$ of responses is known for the test set, it was compared with the estimated season of death vector $(\hat{j})$ and the average of the accuracy (\% of correct predictions) resulting from each split used as the estimate of the feasibility of the model built using the data from all samples. The statistical analyses were performed using the package nnet (Venables \& Ripley, 2002) implemented in the R software (R Development Core Team, 2010).

\section{RESULTS}

The full baseline-category logit regression model for the season of placement of the carcass has 8 covariates: the placement area (with 2 levels: sunlit and shaded) and 

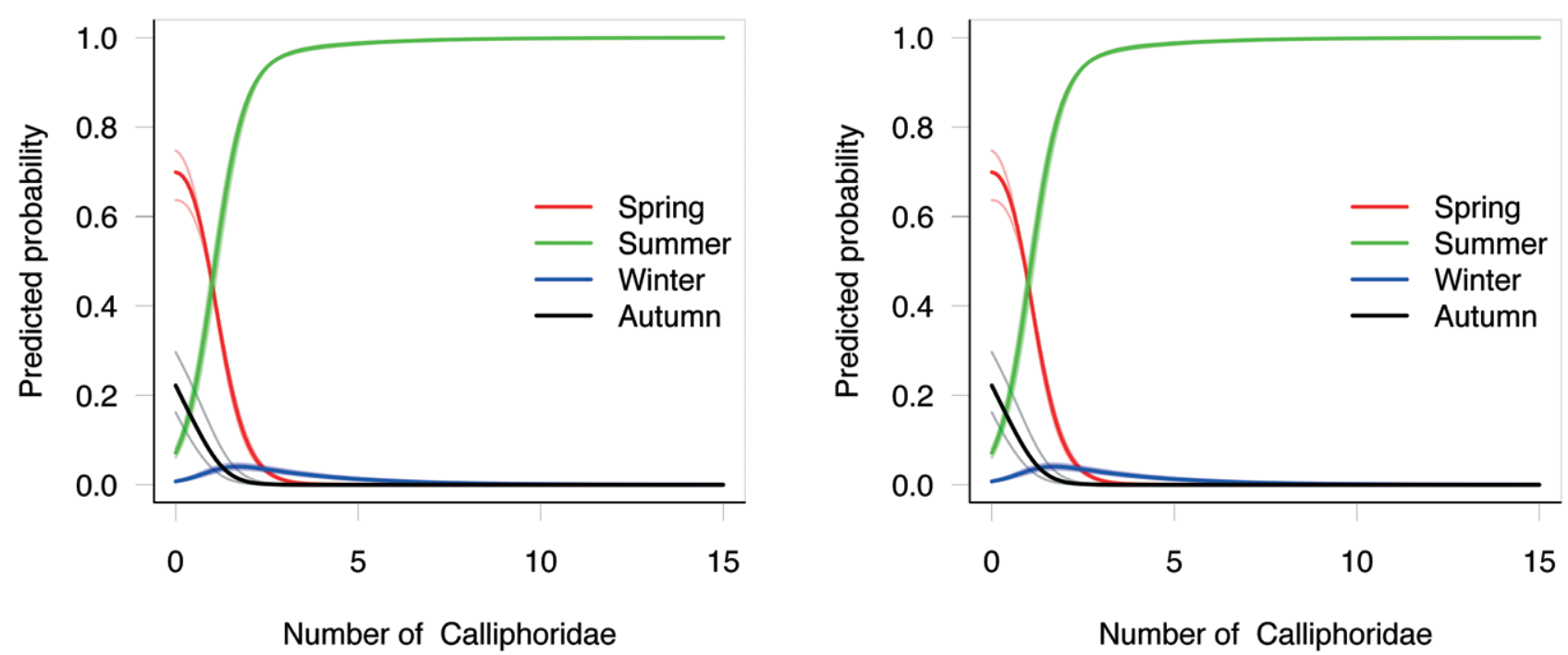

Fig. 2. Estimated probabilities for Calliphoridae depicted as a function of season and exposure of carcass to sun light (95\% CI).

the counts of visiting and/or breeding arthropod families (with 7 levels: Calliphoridae, Encyrtidae, Fanniidae, Formicidae, Otitidae, Sarcophagidae and Syrphidae). The families Anthomyiidae, Asilidae, Apidae, Dolichopodidae, Drosophilidae, Gonyleptidae, Ichneumonidae, Lauxaniidae, Micropezidae, Muscidae, Phoridae, Richardiidae and Sepsidae were not included in the full model because few specimens were collected from the carcasses throughout the whole study $(n<50)$. The abundance of all families of arthropods collected from the 32 rodent carcasses is given in Table 1 .

The backward selection procedure applied to the full model yielded a reduced model with placement area and counts of visiting and/or breeding arthropod families (with 4 levels: Calliphoridae, Fanniidae, Formicidae and
Sarcophagidae) as significant factors. Larvae and adults of these three dipteran families were collected, but only adults of ants. In Table 2, the abundance of the families used in the reduced model is presented by season. Further details on the species composition of the carrion fauna for the study area can be found in Moretti et al. (2008).

The goodness-of-fit of the reduced model to the data assessed by the deviance statistic $(D=1274.93$; d.f. $=$ 1220) showed that the model fits the data very well, because the value of $r(=1.04)$ was close to 1 . The parameter estimates for the reduced model are in Table 3. The performance of this model, measured in terms of overall accuracy, is $64 \pm 14 \%$, which is satisfactorily higher than that obtained by randomly guessing the seasons $(25 \%)$.
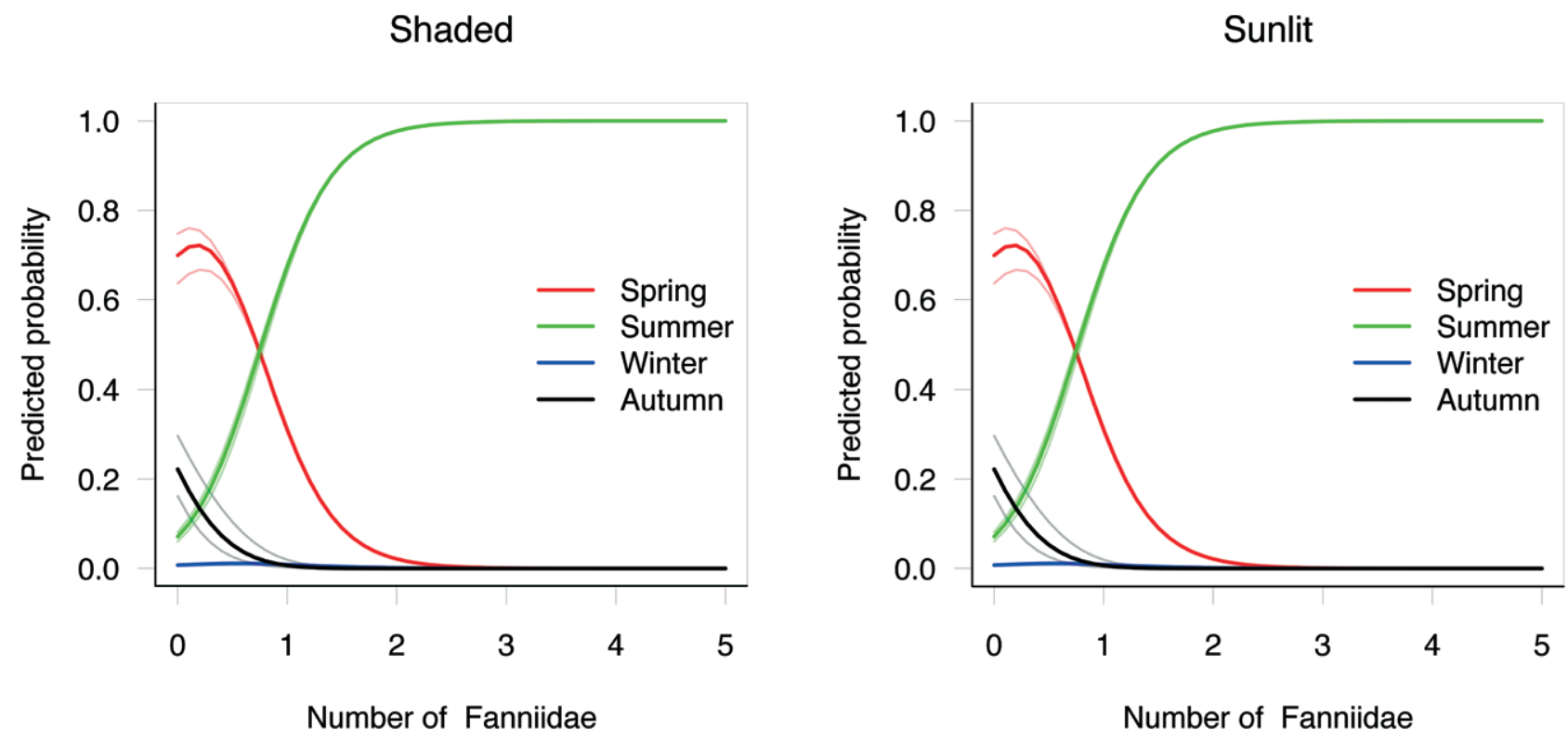

Fig. 3. Estimated probabilities for Fanniidae depicted as a function of season and exposure of carcass to sun light (95\% CI). 
Shaded

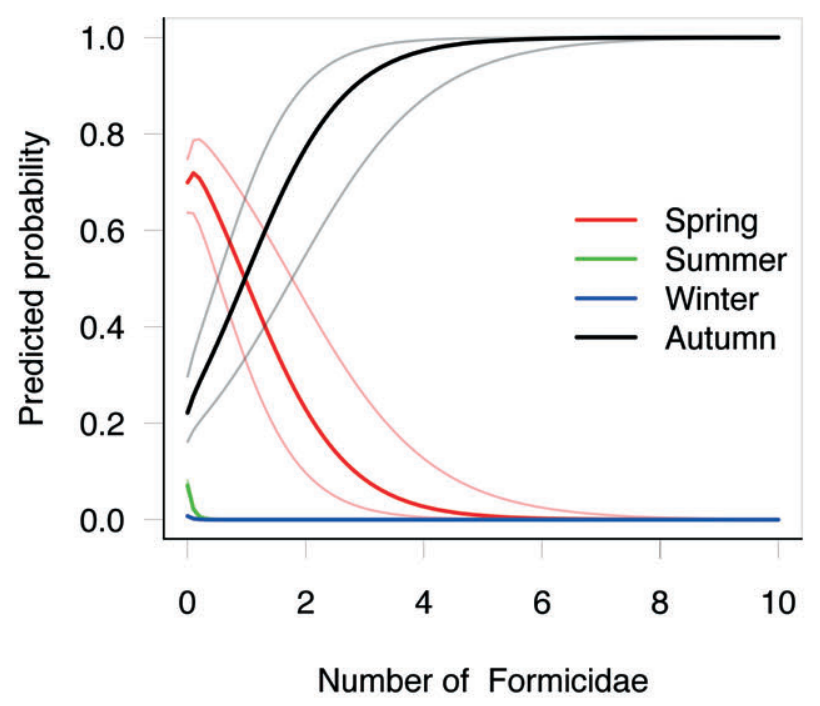

Sunlit

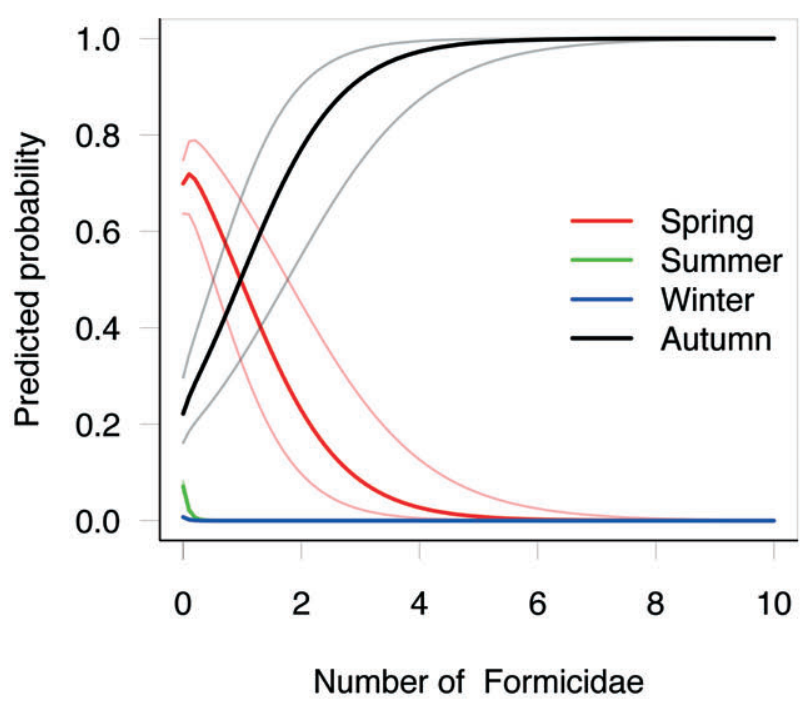

Fig. 4. Estimated probabilities for Formicidae depicted as a function of season and exposure of carcass to sun light (95\% CI).

In Figs 2-5 are the estimated probabilities that a carcass was visited in a particular season based on the counts of visiting and/or the arthropods that bred in the carcasses. Positive coefficients for a particular season (Table 3) indicate that the more individuals of that family were found on the carcass, the greater is the probability that the carcass was placed in the field during that season. Negative coefficients indicate the opposite relationship. For example, according to the model, if a large number of specimens of Sarcophagidae are found in a carcass it strongly indicates that it was placed at the site during winter rather than spring. On the other hand, the more individuals of Calliphoridae and Fanniidae collected, the greater the probability that the carcass was placed at the site during summer. The more Formicidae present on a carcass, the more likely it was present in autumn. How-

\section{Shaded}

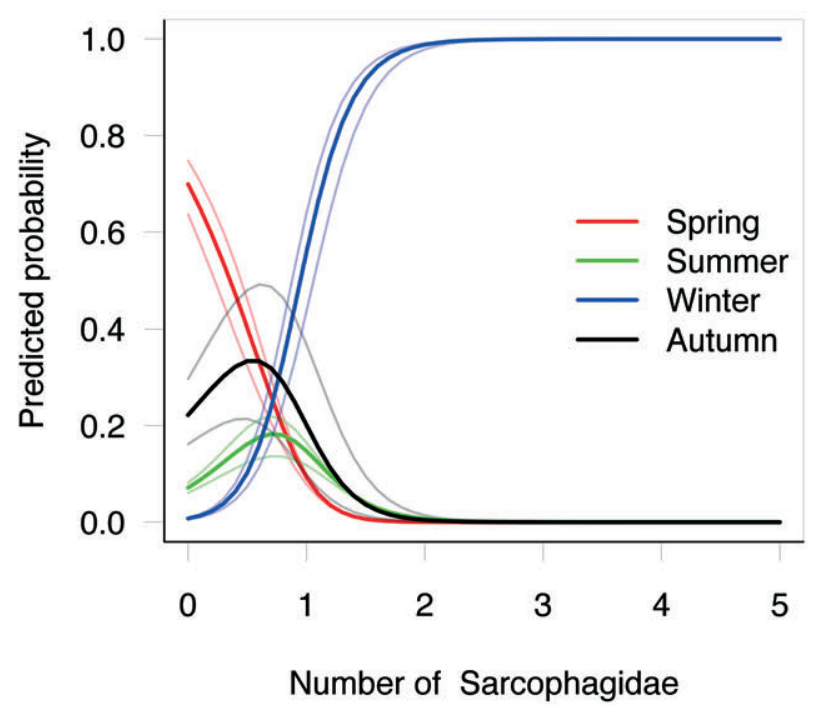

ever, since the coefficients estimated for each visiting arthropod family (Table 3 ) are used simultaneously as a weighting system to identify the season in which a carcass was placed at a site, what governs the final predicted probability of the season in which a carcass was placed in the field is, in fact, the overall relative abundance of these 4 arthropod families. To illustrate this, equation (1) and the values in Table 3 are used to calculate the probability that a carcass was placed in the field during a certain season as a function of the relative abundance of the insect families found on it and of the area in which it was placed (sunlit/shaded). For the following examples it is assumed that the carcasses were placed in a sunlit area. For the first example it is assumed that 10 individuals of each family were collected from the carcass, i.e., relative abundances of 1:1:1:1 for Sarcophagidae, Calliphoridae,

\section{Sunlit}

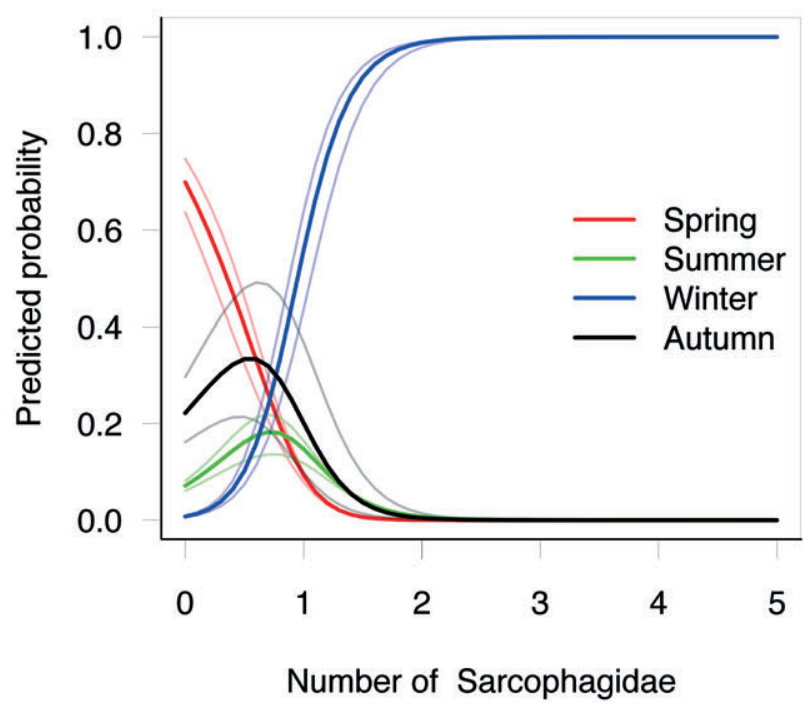

Fig. 5. Estimated probabilities for Sarcophagidae depicted as a function of season and exposure of carcass to sun light (95\% CI) . 
TABLE 3. Parameter estimates used in the reduced model. Standard errors are shown in parentheses.

\begin{tabular}{|c|c|c|c|c|c|c|}
\hline \multirow{2}{*}{ Logit } & \multirow{2}{*}{ Intercept } & \multirow{2}{*}{ Sunlit area } & \multicolumn{4}{|c|}{ Family } \\
\hline & & & Sarcophagidae & Calliphoridae & Fanniidae & Formicidae \\
\hline $\log \left(\pi_{s p}(x) / \pi_{a u}(x)\right)$ & $0.32(0.11)$ & $0.82(0.09)$ & $-1.92(0.20)$ & $0.74(0.10)$ & $2.69(0.34)$ & $-1.18(0.16)$ \\
\hline $\log \left(\pi_{s u}(x) / \pi_{a u}(x)\right)$ & $-3.55(0.12)$ & $2.42(0.10)$ & $0.82(0.19)$ & $3.02(0.12)$ & $5.75(0.32)$ & $-13.15(0.01)$ \\
\hline $\log \left(\pi_{w i}(x) / \pi_{a u}(x)\right)$ & $-3.12(0.14)$ & $-0.27(0.13)$ & $4.40(0.17)$ & $2.60(0.14)$ & $3.65(0.39)$ & $-13.80(0.01)$ \\
\hline
\end{tabular}

$s p$ - spring; $s u$ - summer; wi-winter; $a u$ - autumn.

Fanniidae and Formicidae. In this example, the estimated probability that the carcass was exposed in spring is $98.8 \%$. In a second scenario, with counts of 10:5:5:5 for those families, i.e., relative abundances of $2: 1: 1: 1$, there is an estimated $94.6 \%$ chance that the carcass was placed out in winter. On the other hand, counts (and relative abundances) of 1:1:5:1 for those four families result in a $94.6 \%$ certainty that that the sample came from a carcass placed out in summer. To conclude, a count of 5:5:5:10, i.e., relative abundances of $1: 1: 1: 2$ indicates, with a probability of $95.7 \%$, that it was an autumn carcass.

\section{DISCUSSION}

The results of the study carried out by Souza \& Linhares (1997), in the same area as the present study, support the predictability of the model presented here. They record that the flesh flies Peckia (Pattonella) intermutans Walker, Peckia (Squamatodes) ingens Walker and Sarcophaga (Liopygia) ruficornis Fabricius breed in pig carrion only during the cooler and drier periods of the year (mainly winter) and never in spring and summer. Also, they recorded more adult and immature blow flies (e.g., Chrysomya albiceps Wiedemann, Chrysomya putoria Wiedemann and Lucilia eximia Wiedemann) in summer. This clear seasonal pattern for sarcophagids (peak abundance in winter) is also recorded for human cadavers, in the state of Rio de Janeiro, Brazil (Oliveira-Costa et al., 2001). The Fanniids Fannia pusio Wiedemann (Marchiori \& Prado, 1999) and Fannia canicularis Linnaeus (Byrd \& Castner, 2010), which are tolerant of high temperatures, are more abundant during the warmer summer months, which also supports the findings of the model presented.

Unlike the other arthropods, ants have a quite diverse biology and are not true carrion insects, although there are records of several species of Formicidae consuming vertebrate carcasses (e.g. Moretti et al., 2008). In addition, as they are social and many are capable of recruiting nest mates to resources, it is difficult to decide if one should be counting dozens of individual ants or only a few nests. Moreover, the distance between a carcass and ant nests may affect the presence of Formicidae and may result in the patchy visits of carrion by ants (M. H. Villet, pers. commun.). Therefore, the present model must be interpreted with caution when predicting season of death based on the occurrence of ants. As seen in Figs $2-5$, the predictions were only slightly affected by whether the carcass is in the shade or exposed to sun. Similarly, Souza \& Linhares (1997) found in the same urban forest that insolation does not influence the frequency with which blow flies visit and breed in carcasses.
Byrd \& Castner (2010) conclude that flesh flies are attracted to carrion both in shaded and sunlit areas, with no marked preference. Flesh flies are first recorded on both shaded and exposed carcasses of pigs on the same day in coastal Washington State, which possibly indicates that the insolation regime is not a key factor in the colonization of carcasses by members of this family (Shean et al., 1993). It is unknown whether this factor influences Fanniidae and Formicidae.

Moretti et al. (2008) provide a complete species composition of the local carrion fauna and the possible pattern of insect succession in the study area. This knowledge is vital if entomological tools are to be used in medico-legal routines, or even in cases of wildlife poaching. In this paper, the aim was to use relative abundance data for four forensically important families, Calliphoridae, Sarcophagidae, Fanniidae (Diptera) and Formicidae (Hymenoptera), to model the season of death, which together with the PMI estimation, are the most important forensic aspects (Turchetto \& Vanin, 2010). In the model, immature and adult insects of these families are included because this approach leads to a more complete comprehension of the dynamics of the local carrion community (Michaud \& Moreau, 2009).

From a practical viewpoint, the model is particularly easy to use because it requires that the specimens only be identified to family rather than to species. This is usually achievable, even when the specimens are damaged (e.g. discolored, with broken wings, missing bristles, fragmented). Therefore, entomological remnants e.g. empty puparia, dead larvae, post-feeding larvae, pupae, dead adult flies and ants, must be collected from the corpse and its vicinity, as the number of such remains is likely to indicate the number of living insects previously present on a carcass. Soil samples should be also collected from beneath the corpse and scanned for insect remains. Empty puparia, especially common when a corpse is found a long time after death, are likely to remain in the area for decades (Vanin et al., 2009). Afterwards, all this material must be identified to family level. Crime-scene analysts, death investigators and coroners, who are not necessarily familiar with carrion insects, should be trained to collect, preserve, and identify these remnants to family level. Molecular biology techniques may eventually be used to identify these insect remains (Archer \& Elgar, 2003). Forensic entomologists may be able to help resolve the most complicated cases. Of particular importance of the results presented for forensic science is that the model utilizes specimens that were collected in an outdoor environment in a tropical ecosystem. Therefore, caution is needed when applying this model to indoor areas and 
temperate ecosystems, because of the obvious differences in the weather, species composition of the carrion fauna, succession and seasonal patterns in these two ecosystems.

The overall accuracy of this model is greater than that of a random guess of the season. The model is a first attempt to statistically predict the season of death in tropical systems based on the family composition of the carrion insects and it is now necessary to develop more robust models. Schoenly (1992), who successfully used statistical protocols to estimate PMI from the succession of insects in carrion, points out that statistical approaches or protocols are unusual in forensic entomology, but merit a more extensive use. Logistic regression is utilized to demonstrate that the successional occurrence of some carrion insects can be predicted using accumulation of degree-days and seasonal effects, which may be used to increase the reliability of PMI estimations for a given geographical areas (Michaud \& Moreau, 2009).

Archer \& Elgar (2003) propose a method in which seasonal dating is based on entomological remains left by seasonally active taxa, such as pupal cases of flies and components of the exoskeleton. However, their method depends on identifying insect remains to species level, which may be difficult, even for experienced taxonomists. In addition, the authors collected the insect remains just after the soft tissue was fully decomposed, which increases the chances of identifying them to species level, even of those that are not identifiable after decomposition is complete. If a carcass is sampled long after decomposition is complete, which is common in forensic analyses, it is often very difficult to identifying the insect remains to species level, which greatly reduces the efficiency of this method.

The potential application of the results of this study to forensic entomology must be evaluated with caution, since the experimental model (small rodent carcass) differs from the most-commonly used carcass, the domestic pig Sus scrofa L. (Catts \& Goff, 1992).

Nevertheless, following a study in an urban environment at Curitiba in southern Brazil, Moura et al. (1997) conclude that the carrion entomofauna collected from rodent carcasses does not differ from that collected from pig carcasses (Souza \& Linhares, 1997) and human corpses (Salviano et al., 1996). Also, the general seasonal pattern of utilization of rodent and human carcasses by insects is similar (Moura et al., 1997). Moreover, because the model presented uses the relative abundance of carrion insects (i.e. the changing proportions of the four families) (i) the size of the carcass does not influence the prediction power of the model and (ii) exhaustive collections of insect remains are not required. Therefore, not only is this model easier to use in terms of the logistics and fieldwork required compared to the models developed for pig carcasses and human corpses, but also its predictions are robust.

\section{Ethical standards}

All procedures for killing the rodents and using their carcasses followed the ethical norms of the Brazilian College of Animal Experimentation (COBEA).
ACKNOWLEDGEMENTS. T.C.M. was funded by a scholarship from FAPESP (The State of São Paulo Research Foundation) (grant no. 06/60504-9) and W.A.C.G. was partially funded by $\mathrm{CNPq}$ (The National Council for Scientific and Technological Development). We thank M.H. Villet (Rhodes University, South Africa) for his constructive comments.

\section{REFERENCES}

Agresti A. 2002: Categorical Data Analysis. John Wiley and Sons, New Jersey, 734 pp.

ANDERson G.S. 2010: Factors that influence insect succession on carrion. In Byrd J.H. \& Castner J.L. (eds): Forensic Entomology: The Utility of Arthropods in Legal Investigations. CRC Press, Boca Raton, pp. 201-250.

Archer M.S. \& Elgar M.A. 2003: Yearly activity patterns in southern Victoria (Australia) of seasonally active carrion insects. Forensic Sci. Int. 132: 173-176.

BLACKITH R.E. \& BLACKITH G.R. 1990: Insect infestation of small corpses. J. Nat. Hist. 24: 699-709.

BYRD J.H. \& CASTNER J.L. 2010: Insects of forensic importance. In Byrd J.H. \& Castner J.L. (eds): Forensic Entomology: The Utility of Arthropods in Legal Investigations. CRC Press, Boca Raton, pp. 39-126.

CatTs E.P. \& GofF M.L. 1992: Forensic entomology in criminal investigations. Annu. Rev. Entomol. 37: 253-272.

Cepagri - Centro de Pesquisas Meteorológicas e Climáticas Aplicadas à Agricultura. Clima de Campinas. Available at: $<$ http://www.cpa.unicamp.br/outras-informacoes/clima-de-ca mpinas.html>.

DAVIES L. 1999: Seasonal and spatial changes in blowfly production from small and large carcasses at Durham in lowland northeast England. Med. Vet. Entomol. 13: 245-251.

Draper N.R. \& SMith H. 1981: Applied Regression Analysis. John Wiley and Sons, New Jersey, 407 pp.

Geberth V.J. 1996: Practical Homicide Investigation. CRC Press, Boca Raton, 901 pp.

Henssge C., Knight B., Krompecher T., Madea B. \& Nokes L. 2002: The Estimation of the Time since Death in the Early Postmortem Period. Arnold, London, 271 pp.

Isiche J., Hillerton J.E. \& Nowell F. 1992: Colonization of the mouse cadaver by flies in southern England. Med. Vet. Entomol. 6: 168-170.

Kentner E. \& Streit B. 1990: Temporal distribution and habitat preference of congeneric insect species found at rat carrion. Pedobiologia 34: 347-359.

Marchiori C.H. \& Prado A.P. 1999: Tabelas de Vida de Fannia pusio (Wied.) (Diptera: Fanniidae). Neotrop. Entomol. 28: 557-563.

McCullagh P. \& Nelder J.A. 1989: Generalized Linear Models. Chapman and Hall, New York, 511 pp.

Michaud J.P. \& Moreau G. 2009: Predicting the visitation of carcasses by carrion-related insects under different rates of degree-day accumulation. Forensic Sci. Int. 185: 78-83.

Monteiro-Filho E.L.A. \& Penereiro J.L. 1987: A study on decomposition and succession on animal carcasses in an area of São Paulo, Brazil. Braz. J. Biol. 47: 289-295.

Moretti T.C. \& Ribeiro O.B. 2006: Occurrence of the parasitoid Tachinaephagus zealandicus (Ashmead) (Hymenoptera: Encyrtidae) in pupae of Chrysomya megacephala (Fabricius) (Diptera: Calliphoridae) in rat carcass. Arq. Bras. Med. Vet. Zootec. 58: 137-140.

Moretti T.C., Ribeiro O.B., Thyssen P.J. \& Solis D.R. 2008: Insects on decomposing carcasses of small rodents in a secondary forest in Southeastern Brazil. Eur. J. Entomol. 105: 691-696. 
Moura M.O., Carvalho C.J.B. \& Monteiro-Filho E.L.A. 1997: A preliminary analysis of insects of medico-legal importance in Curitiba, State of Paraná. Mem. Inst. Oswaldo Cruz 92: 269-274.

Oliveira-Costa J., Mello-Patiu C.A. \& Lopes S.M. 2001: Muscoid Diptera associated with human corpses at the death scene in the State of Rio de Janeiro, Brazil. Bol. Mus. Nac. N. S. (Zool.) 464: 1-6.

R Development Core Team 2010: $R$ : A Language and Environment for Statistical Computing. R Foundation for Statistical Computing, Vienna, Austria. URL http://www.R-project.org.

Salviano R.J.B., Mello R.P., Santos R.F.S., Beck L.C.N.H. \& FERreira A. 1996: Calliphoridae (Diptera) associated with human corpses in Rio de Janeiro, Brazil. Entomol. Vect. 3 : $145-146$.

Schoenly K. 1992: A statistical analysis of successional patterns in carrion-arthropod assemblages: implications for forensic entomology and determination of the postmortem interval. $J$. Forensic Sci. 37: 1489-1513.

Schoenly K., Goff M.L. \& Early M. 1992: A BASIC algorithm for calculating the postmortem interval from arthropod successional data. J. Forensic Sci. 37: 808-823.
Shean B.S., Messinger L. \& Papworth M. 1993: Observations of differential decomposition on sun exposed v. shaded carrion in coastal Washington State. J. Forensic Sci. 38: 938-949.

SouzA A.M. \& Linhares A.X. 1997: Diptera and Coleoptera of potential forensic importance in Southeastern Brazil: relative abundance and seasonality. Med. Vet. Entomol. 11: 8-12.

TOMBERlin J.K. \& AdLeR P.H. 1998: Seasonal colonization and decomposition of rat carrion in water and on land in an open field in South Carolina. J. Med. Entomol. 35: 704-709.

Turchetto M. \& Vanin S. 2010: Climate change and forensic entomology. In Amendt J., Goff M.L., Campobasso C.P. \& Grassberger M. (eds): Current Concepts in Forensic Entomology, Springer, Dordrecht, pp. 327-351.

Vanin S., Turchetto M., Galassi A. \& Cattaneo C. 2009: Forensic entomology and the archaeology of war. J. Conflict Archaeol. 5: 127-139.

Venables W.N. \& Ripley B.D. 2002: Modern Applied Statistics with $S$. Springer, New York, 495 pp.

Received September 20, 2010; revised and accepted December 12, 2010 